\title{
Surge Motion Passive Control of TLP with Double Horizontal Tuned Mass Dampers
}

\author{
Mohammad Reza Tabeshpour and Ebrahim Malayjerdi \\ Center of Excellence in Hydrodynamics and Dynamics of Marine Vehicles, Mechanical Engineering Department, \\ Sharif University of Technology, Tehran.
}

(Received 25 August 2016; accepted 2 February 2018)

\begin{abstract}
The tension leg platform (TLP) is comprised of a buoyant hull that holds the platform's topside. A group of tendons under the columns connect the TLP to the foundation. The TLP is displaced in six degrees of freedom due to environmental loads. Tendons moor the TLP in vertical direction (heave and pitch). Surge amplitude (horizontal displacement) of TLP is greater than other degrees of freedom. Also heave motion is coupled with surge one. Therefore, it is important to introduce and implement a method to control and reduce displacement of the TLP in horizontal direction. In this paper, a passive control system (double horizontal tuned mass damper (TMD)) is used to mitigate the surge motion of TLP that is under regular waves. Also the efficiency and performance of double horizontal TMD and single horizontal TMD in reduction of surge response is compared.
\end{abstract}

\section{INTRODUCTION}

The Tension Leg Platform (TLP) is a hybrid structure. With respect to horizontal degrees of freedom, it is compliant and behaves like a floating structure. With respect to the vertical degrees-of-freedom, it is stiff and resembles a fixed structure and is not allowed to float freely. ${ }^{1}$ When a wave load excites TLP in horizontal direction, it is displaced in surge, heave and pitch directions. Tendons cause to moor TLP in a vertical direction (heave and pitch). So, displacement of TLP in a vertical displacement is significantly lower than a horizontal displacement. The range of a natural period of surge motion for TLP is between 60 to 100 seconds.

Some studies have investigated the vibrations of floating structures and the control of these structures. The stochastic response of a TLP subjected to viscous and potential drift forces is presented by Donley et al. ${ }^{2}$ Chatterjee et al. conducted hydrodynamic and structural analyses for two TLP models, and one of models is ISSC TLP. ${ }^{3}$ Tabeshpour et al. focused on the comprehensive interpretation of the responses of the structure related to wave excitation and structural characteristics. ${ }^{4}$ Tabeshpour and Malayjerdi researched pitch motion portion in vertical response at the sides of a TLP. ${ }^{4}$

Rosane and Batista investigated passive and active control of the heave motion of a TLP. ${ }^{5} \mathrm{Li}$ and Zhou evaluated multiple active lever-type tuned mass damper for under ground motion structures. ${ }^{6}$ Response mitigation of the offshore floating platform system with tuned liquid column damper is studied by Lee et al. ${ }^{7} \mathrm{Li}$ and Zhou proposed a double tuned mass dampers for reduction of vibrations of structures under ground acceleration. ${ }^{8}$ F. Rudinger conducted a survey on the effect of tuned mass dampers with nonlinear viscous damping elements on a structure that was excited by a white noise. ${ }^{9}$ Performances of tuned mass dampers and friction dampers to mitigate the wave induced vibrations in jacket type offshore platforms have been compared by Golafshani and Gholizad. ${ }^{10}$ A simulationbased robust design of mass dampers for response mitigation of TLP was presented by Taflanidis et al. ${ }^{11}$ Chandrasekaran et al. studied the dynamic response behavior of a multi-legged articulated tower with and without TMD. ${ }^{12}$ Also dynamic response of TLP with tuned mass dampers was examined by Chandrasekaran et al. ${ }^{13}$ Chatterjee and Chakraborty (2014) conducted a survey on vibration mitigation of structures subjected to random wave forces by liquid column dampers. ${ }^{14}$

This paper focuses on vibration mitigation of TLP in a horizontal direction. A passive device (double horizontal TMD) is installed on a TLP subjected to regular waves and the effects of it in response mitigation is investigated. Also, the performance of double horizontal TMD is compared with single horizontal TMD.

\section{DYNAMIC PARAMETERS OF TMD}

The idea of reducing roll motions and also reducing deck oscillations on ships for the first time was raised by Frahm in 1909. The theory of TMD was presented by Ormondroyd and Den Hartog et al. ${ }^{15}$ Den Hartog, in the book of Mechanical Vibration, dealt with more detailed discussions about the optimal values of damping and vibration frequency of the TMD. TMD is a passive damping system that utilizes a secondary mass that is attached to the main structure through spring and dashpot. The secondary mass system has a natural period that is close to the period of primary structure which depends on its mass and stiffness. The excess energy that is built up in the structure can be transferred to a secondary mass and is dissipated by the TMD.

The following parameters are used in designing a TMD:

$$
\omega^{2}=\frac{k}{M}, \omega_{d}^{2}=\frac{k_{d}}{m_{d}}, C_{d}=2 \xi_{d} \omega_{d} m_{d} ;
$$

where $\omega, k$ and $M$ are natural frequency, stiffness and mass of primary system respectively, $\omega_{d}, k_{d}, m_{d}, c_{d}$ and $\zeta_{d}$ are natural frequency, stiffness, mass, damping coefficient and damping ratio of TMD respectively. Some ratios are defined as follows:

$$
\bar{m}=\frac{m_{d}}{M}, f=\frac{\omega_{d}}{\omega}, \rho=\frac{\Omega}{\omega} ;
$$

where $\bar{m}$ is the ratio of the damper mass to the system mass, $f$ is the ratio of the natural frequency of damper to a primary 
system, $\rho$ is the ratio of the frequency of excitation to primary mass. The optimal frequency ratio can be calculated using the following equation:

$$
f_{\text {opt }}=\frac{1}{1+\bar{m}}, \omega_{d \mid o p t}=f_{o p t} \times \omega
$$

The optimal damping can be calculated using the following equation:

$$
\zeta_{o p t}=\sqrt{\frac{\bar{m}}{(1+\bar{m})^{3}}} .
$$

When the mass ratio of the secondary mass to the primary body $\bar{m}$ is determined, the next step is to calculate the optimum frequency ratio $f_{\text {opt }}$ and the optimum damping ratio $\zeta_{\text {opt }}$. Eventually $\omega_{\text {opt }} k_{d}$ and $c_{d}$ will be calculated.

\section{VIBRATION CONTROL OF SURGE MOTION WITH DOUBLE HORIZONTAL TMD}

The double horizontal TMD consists of one larger mass block (i.e. one larger TMD) and one smaller mass block (i.e. one smaller TMD) Lee et al. ${ }^{7}$ Smaller TMD is placed on the large TMD and leads to reducing the displacement of the larger TMD. At the end, such a system results in decreasing the response of the main system. Also, the total number of degrees-of-freedom of the horizontal double TMD structure system is equal to 2, as shown in Fig. 2. The relevant analysis has been carried out based on a combination of this system with TLP. The equations of motion can be expressed as follows:

$$
\begin{aligned}
& \left(M+A_{11}+\left(m_{d}\right)_{1}\right) \ddot{x}+k_{11} x= \\
& F_{11}+\left(c_{d}\right)_{1}\left(\dot{x}_{1}-\dot{x}\right)+\left(k_{d}\right)_{1}\left(x_{1}-x\right) ; \\
& \left(x_{d}\right)_{1}=x_{1}-x \quad,\left(\dot{x}_{d}\right)_{1}=\dot{x}_{1}-\dot{x} \Rightarrow \\
& \left(M+A_{11}+\left(m_{d}\right)_{1}\right) \ddot{x}+k_{11} x= \\
& F_{11}+\left(c_{d}\right)_{1}\left(\dot{x}_{d}\right)_{1}+\left(k_{d}\right)_{1}\left(x_{d}\right)_{1} \text {; } \\
& \left(m_{d}\right)_{1} \ddot{x}_{1}+\left(c_{d}\right)_{1}\left(\dot{x}_{1}-\dot{x}\right)+\left(c_{d}\right)_{2}\left(\dot{x}_{1}-\dot{x}_{2}\right) \\
& +\left(k_{d}\right)_{1}\left(x_{1}-x\right)+\left(k_{d}\right)_{2}\left(x_{1}-x_{2}\right)=0 ; \\
& \left(\begin{array}{l}
\left(x_{d}\right)_{1}=x_{1}-x \quad, \quad\left(\dot{x}_{d}\right)_{1}=\dot{x}_{1}-\dot{x} \\
\left(x_{d}\right)_{2}=x_{2}-x_{1} \quad, \quad\left(\dot{x}_{d}\right)_{1}=\dot{x}_{2}-\dot{x}_{2}
\end{array}\right) \Rightarrow \\
& \left(m_{d}\right)_{1}\left(\left(\ddot{x}_{d}\right)_{1}+\ddot{x}\right)+\left(c_{d}\right)_{1}\left(\dot{x}_{d}\right)_{1}-\left(c_{d}\right)_{2}\left(\dot{x}_{d}\right)_{2} \\
& +\left(k_{d}\right)_{1}\left(x_{d}\right)_{1}-\left(k_{d}\right)_{2}\left(x_{d}\right)_{2}=0 \Rightarrow \\
& \left(m_{d}\right)_{1}\left(\ddot{x}_{d}\right)_{1}+\left(c_{d}\right)_{1}\left(\dot{x}_{d}\right)_{1}+\left(k_{d}\right)_{1}\left(x_{d}\right)_{1}= \\
& -m_{d} \ddot{x}+\left(c_{d}\right)_{2}\left(\dot{x}_{d}\right)_{2}+\left(k_{d}\right)_{2}\left(x_{d}\right)_{2} \text {; } \\
& \left(m_{d}\right)_{2} \ddot{x}_{2}+\left(c_{d}\right)_{2}\left(\dot{x}_{2}-\dot{x}_{1}\right)+\left(k_{d}\right)_{2}\left(x_{2}-x_{1}\right)=0 ; \\
& \left(\begin{array}{c}
\left(x_{d}\right)_{1}=x_{1}-x \quad, \quad\left(\dot{x}_{d}\right)_{1}=\dot{x}_{1}-\dot{x} \\
\left(x_{d}\right)_{2}=x_{2}-x_{1} \quad, \quad\left(\dot{x}_{d}\right)_{1}=\dot{x}_{2}-\dot{x}_{2}
\end{array}\right) \Rightarrow
\end{aligned}
$$
control surge motion. b) Main system (TLP) with system of double TMD.

Figure 1. a) Schematic view of double TMD in the center of the platform to

(a)

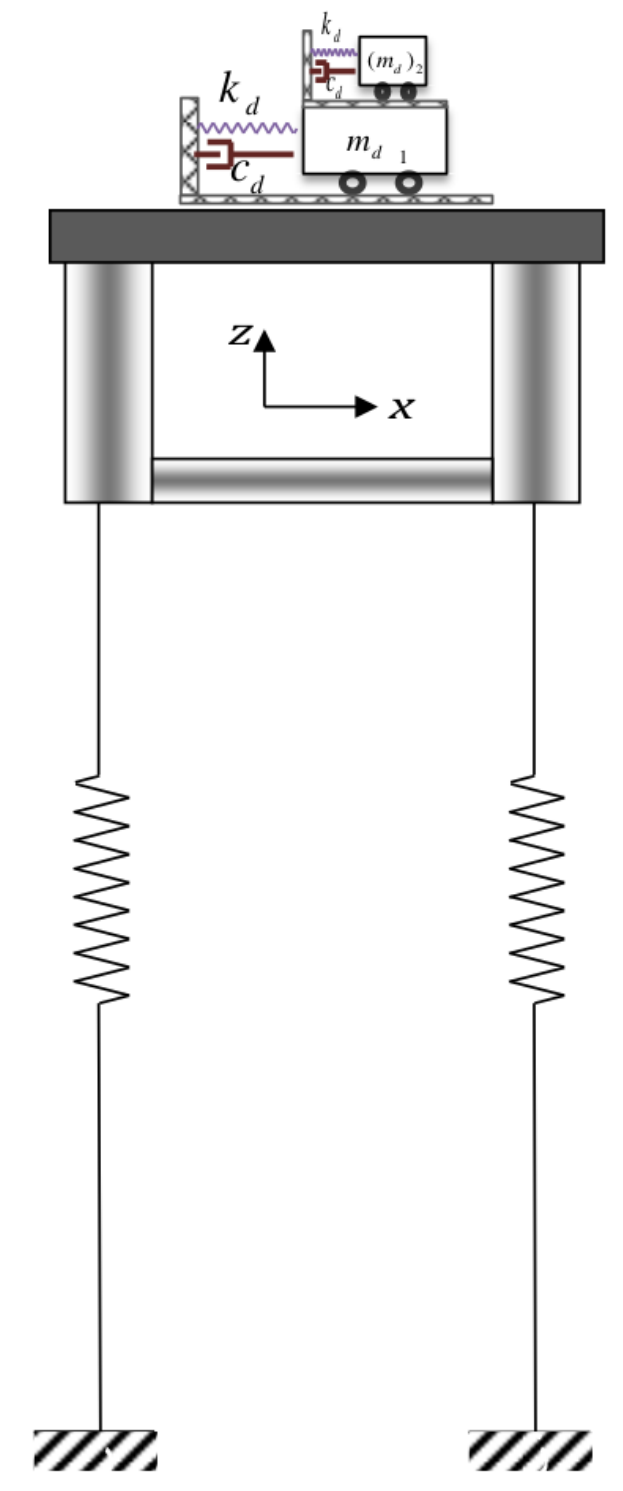

(b)

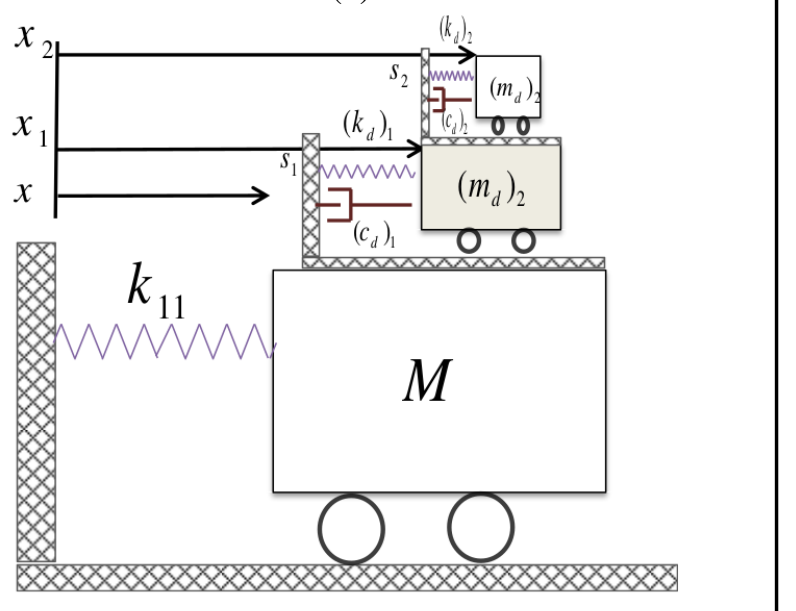




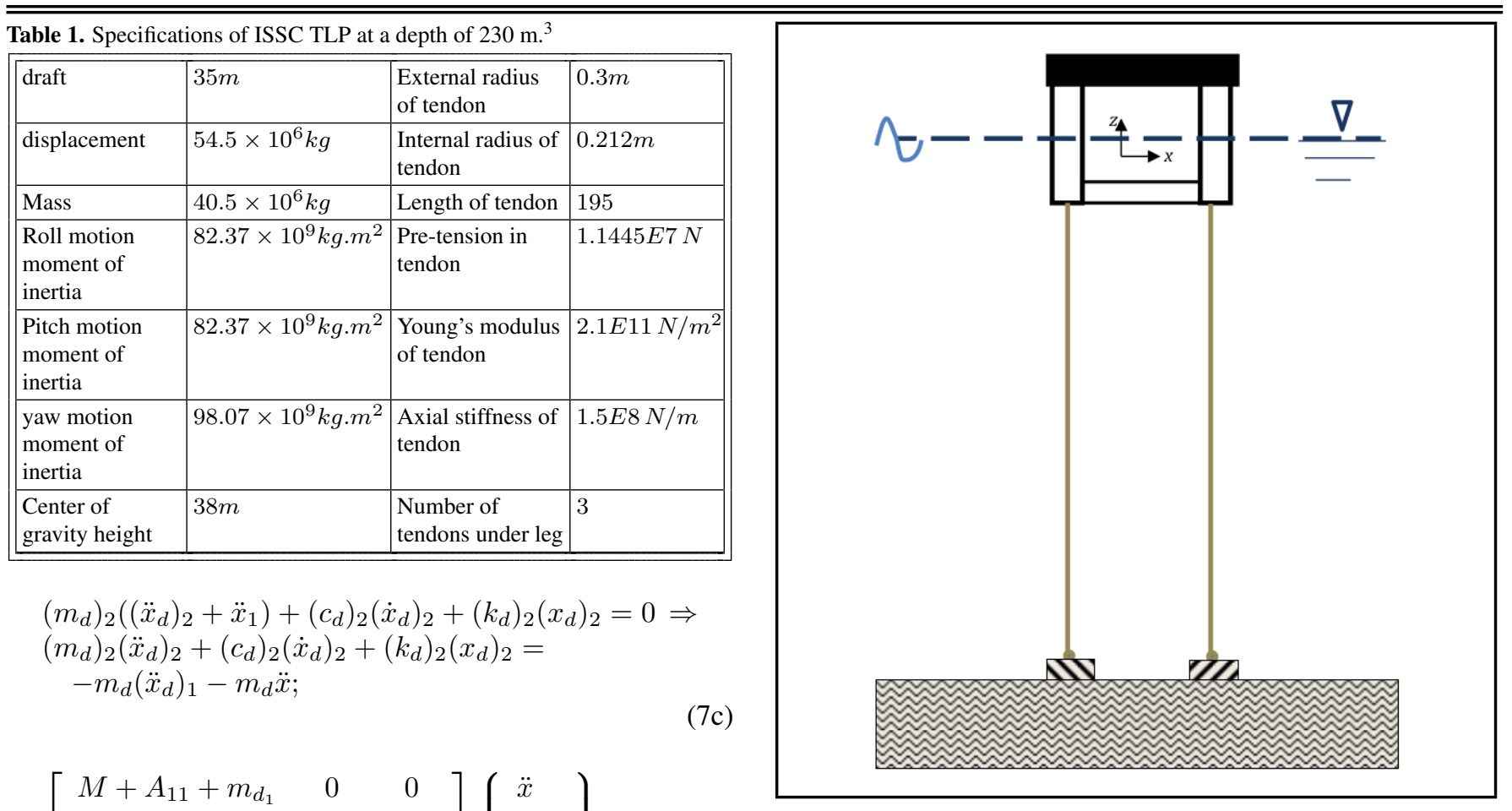

$$
\begin{gathered}
{\left[\begin{array}{ccc}
M+A_{11}+m_{d_{1}} & 0 & 0 \\
m_{d} & m_{d_{1}} & 0 \\
m_{d} & m_{d} & m_{d_{2}}
\end{array}\right]\left\{\begin{array}{l}
\ddot{x} \\
\ddot{x}_{d_{1}} \\
\ddot{x}_{d_{2}}
\end{array}\right\}} \\
+\left[\begin{array}{ccc}
0 & 0 & 0 \\
0 & c_{d_{1}} & -c_{d_{2}} \\
0 & 0 & c_{d_{2}}
\end{array}\right]\left\{\begin{array}{l}
\dot{x} \\
\dot{x}_{d_{1}} \\
\dot{x}_{d_{2}}
\end{array}\right\} \\
+\left[\begin{array}{ccc}
k_{11} & -k_{d} & 0 \\
0 & k_{d_{1}} & -k_{d_{2}} \\
0 & 0 & k_{d_{2}}
\end{array}\right]\left\{\begin{array}{l}
\dot{x} \\
\dot{x}_{d_{1}} \\
\dot{x}_{d_{2}}
\end{array}\right\}=\left\{\begin{array}{l}
F \\
0 \\
0
\end{array}\right\} ;
\end{gathered}
$$

where $M, A_{11},\left(m_{d}\right)_{1}$ and $\left(m_{d}\right)_{2}$ are the platform mass, added mass in the horizontal direction, mass of larger TMD and mass of smaller TMD respectively. $k_{11},\left(k_{d}\right)_{1}$ and $\left(k_{d}\right)_{1}$ are the stiffness of platform in surge direction, stiffness of larger TMD, stiffness of smaller TMD respectively. $c_{11},\left(c_{d}\right)_{1}$ and $\left(c_{d}\right)_{1}$ are damping of platform in surge direction, stiffness of larger TMD and stiffness of smaller TMD respectively, and $F_{11}$ is the hydrodynamic force in the horizontal direction.

According to Fig. 1, $x$ is the surge displacement of the main structure with reference to the ground, $x_{1}$ expresses the displacement of larger TMD with reference to the ground and $x_{2}$ represents the displacement of smaller TMD with reference to the ground. $\left(x_{d}\right)_{1}$ is displacement of the larger TMD with reference to $s_{1}$ (relative displacement) and $\left(x_{d}\right)_{2}$ is displacement of smaller TMD with reference to $s_{2}$.

\section{CASE STUDY}

The case study is a TLP that is shown as a schematic view in Fig. 2 named ISSC TLP with specifications that are given in Tab. $1 .^{3}$

\section{DYNAMIC CHARACTERISTICS OF TMDS}

In Tabs. 2-3 dynamic characteristics of double and single TMD are presented respectively. The desired mass ratio $(\bar{m})$ for two cases is considered 0.02 .
Figure 2. Schematic view of case study.

Table 2. Dynamic characteristics of double TMD.

\begin{tabular}{|l|l|l|l|}
\hline \multicolumn{4}{|c|}{ Damper properties } \\
\hline$T_{n}$ & $m_{d}$ & $k_{d}$ & $c_{d}$ \\
\hline$T_{n}($ surge $)=72 s$ & $\left(m_{d}\right)_{1}=$ & $(k d)_{1}=$ & $\left(c_{d}\right)_{1}=$ \\
& $1806300 \mathrm{~kg}$ & $10045.61 \frac{\mathrm{N}}{\mathrm{m}}$ & $5388.2 \frac{\mathrm{N} . s}{\mathrm{~m}}$ \\
& $\left(m_{d}\right)_{2}=$ & $(k d)_{2}=$ & $\left(c_{d}\right)_{2}=$ \\
& $36126 \mathrm{~kg}$ & $181.323 \frac{\mathrm{N}}{\mathrm{m}}$ & $102.37 \frac{\mathrm{N} . \mathrm{s}}{\mathrm{m}}$ \\
\hline
\end{tabular}

Table 3. Dynamic characteristics of single TMD.

\begin{tabular}{|l|l|l|l|}
\hline \multicolumn{4}{|c|}{ Damper properties } \\
\hline$T_{n}$ & $m_{d}$ & $k_{d}$ & $c_{d}$ \\
\hline$T_{n}($ surge $)=72 \mathrm{~s}$ & $1806300 \mathrm{~kg}$ & $10045.61 \frac{\mathrm{N}}{\mathrm{m}}$ & $5388.1929 \frac{\mathrm{N}}{\mathrm{m}}$ \\
\hline
\end{tabular}

\section{NUMERICAL RESULTS}

The surge response is obtained by solving equations of motion. The encounter wave is assumed linear, based on Airy theory. Table 4 presents characteristics of the approaching waves for analyses.

Figures 3-4 illustrate the time history of a surge response with and without double TMD and Fast Fourier Transform (FFT) of these responses for load cases W1 and W2 respectively. In this paper, FFT is used to depict amplitude of displacement in the frequency domain. It is important to note the behavior of TLP and achieve an understanding of what effect TMD has in different wave periods. FFT reports when the exact wave period peak of displacement occurs.

It is seen in Figs. 3-4 that there are two peaks in FFT of surge response. The first peak is related to the incident wave period and the second one occurs in the natural period of surge

Table 4. Characteristics of the approaching waves for analyses.

\begin{tabular}{|l|l|l|}
\hline Load case & Wave Period $(\mathrm{s})$ & Wave Height $(\mathrm{m})$ \\
\hline W1 & $T=8 \mathrm{~s}$ & $H=8 \mathrm{~m}$ \\
W2 & $T=12 \mathrm{~s}$ & $H=10 \mathrm{~m}$ \\
\hline
\end{tabular}




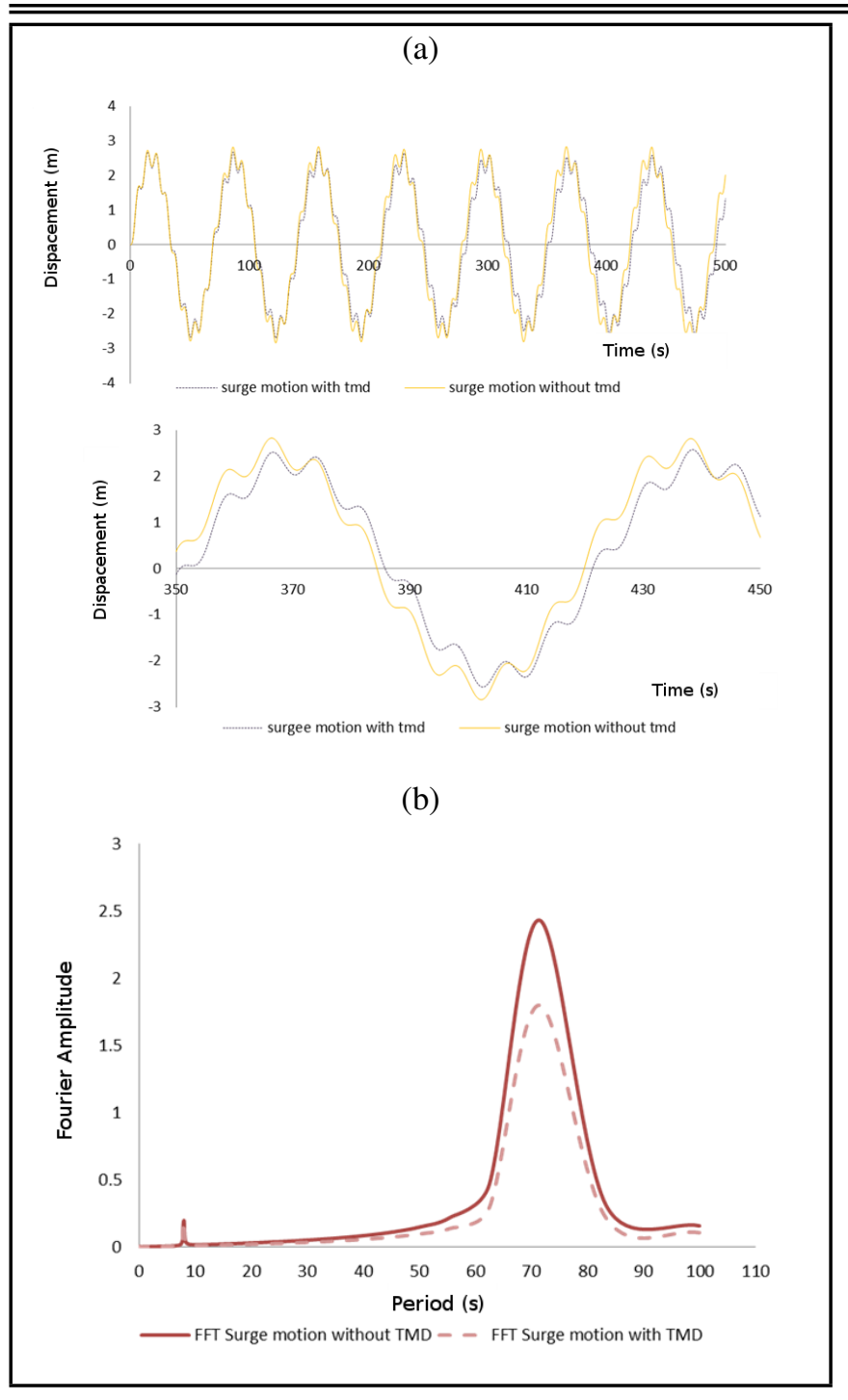

Figure 3. a) Time history of response of surge motion with and without double TMD for load case W1. b) FFT of these responses.

motion. There is no mitigation in the surge response in the first peak, but the second peak is relatively reduced. Also the efficiency of double TMD for suppressing the surge response for $\mathrm{W} 1$ is more than $\mathrm{W} 2$ because the natural period of TMD is tuned with the natural period of surge motion at $72 \mathrm{~s}$. Therefore, in the wave period $12 \mathrm{~s}$ which is closer than the wave period 8 sto the natural period of surge, response mitigation is more. When TLP is excited by load case W1, the amplitude of surge without TMD is equal to $2.8 \mathrm{~m}$ and when double TMD is added to TLP, it is close to $2.4 \mathrm{~m}$. When load case W2 encounter TLP, amplitude of surge with and without double TMD is equal to $7.3 \mathrm{~m}$ and 6 respectively. The reduction percent of surge displacement for load case W1 and W2 is close to $14 \%$ and $17 \%$.

The Fourier amplitude of surge motion with double and single TMD and surge motion without TMD for load cases W1 and W2 are shown in Figures 5-6 respectively. When comparing Figs. 5-6, it demonstrates that Fourier amplitude of surge motion with double TMD in the second peak (natural period of surge) is reduced more than single TMD. When TLP is controlled by single TMD, the mitigation percent of surge response for load cases $\mathrm{W} 1$ and $\mathrm{W} 2$ is equal to $10 \%$ and $12 \%$. In double TMD, displacement of larger TMD is suppressed by (a)

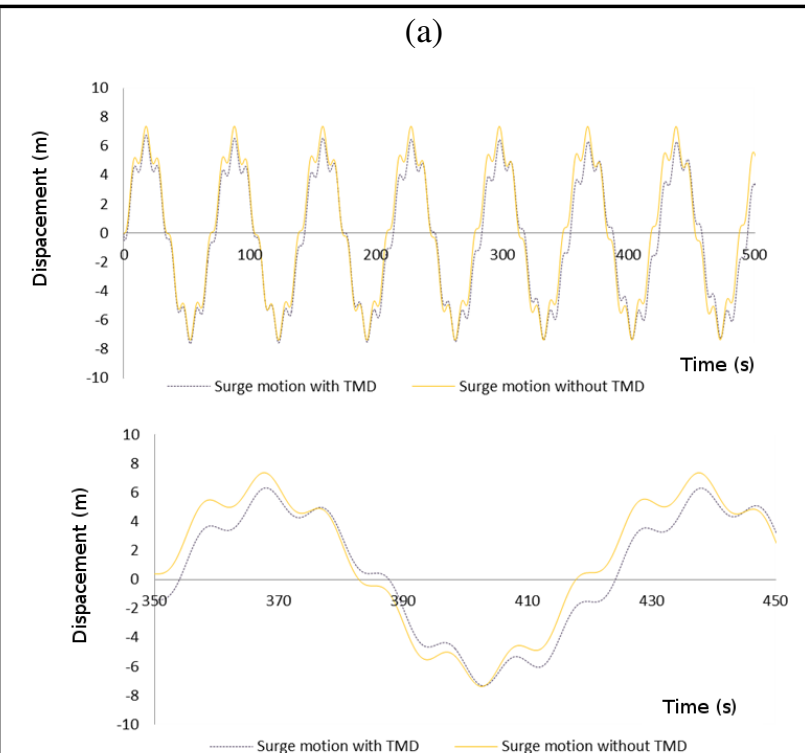

(b)

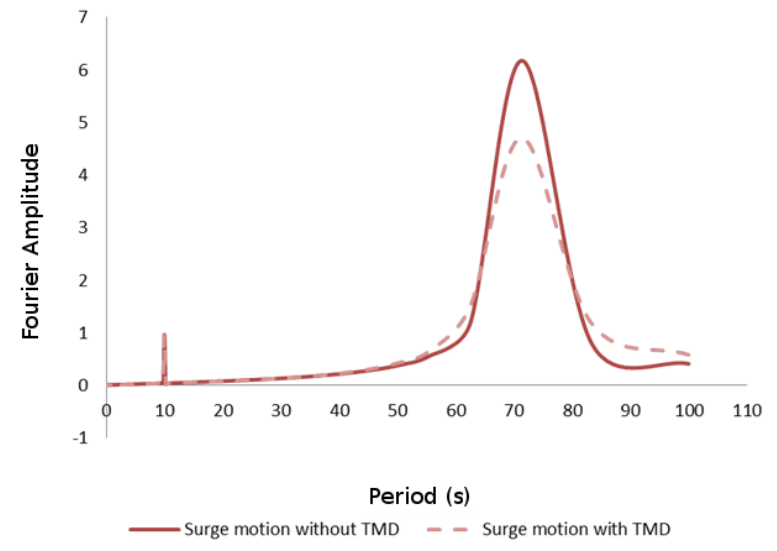

Figure 4. a) Time history of response of surge motion with and without double TMD for load case W2. b) FFT of these responses for load case W2.

a smaller one.Therefore, displacement of larger TMD in this case is less than single TMD. Displacement of TMD is an important point in designing because TMD usually has a large displacement and a large space is occupied in the topside of TLP.

\section{CONCLUSION}

In the present study, the surge response of TLP controlled by passive systems (i.e. doubles and single TMD) under wave loading was investigated. From the numerical results, the following points were obtained:

1. TMD was not efficient in the period of the incident wave, but it could reduce surge displacement in a natural period of surge motion, because TMD was tuned with dynamic properties of the surge motion.

2. Response reduction of TLP with double TMD subjected to load cases W1 $(H=8 m, T=8 s)$ and $\mathrm{W} 2(H=$ $10 \mathrm{~m}, T=12 \mathrm{~s}$ ) are equal to $14 \%$ and $17 \%$. It seems the efficiency of TMD in high wave period was more than the low period. 


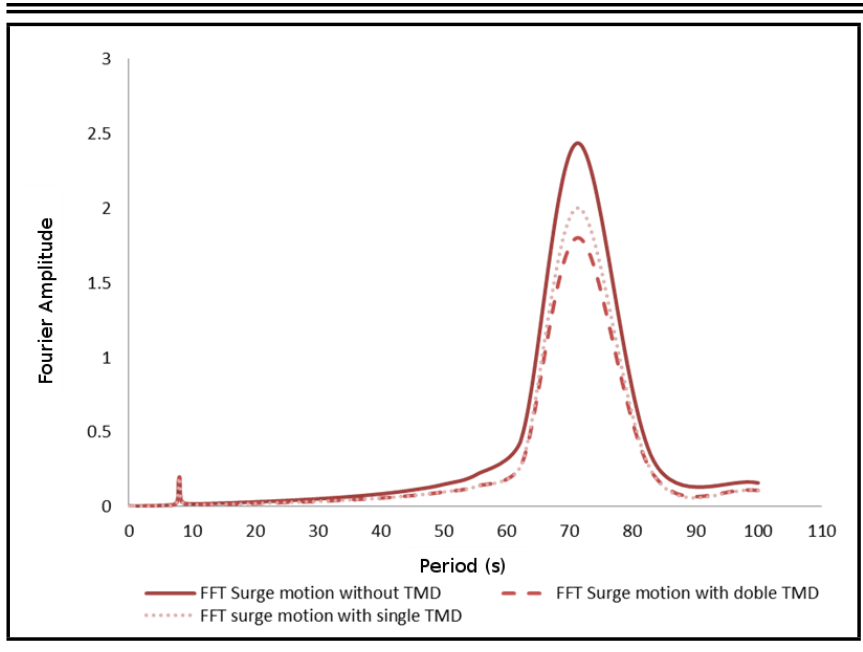

Figure 5. FFT surge response of TLP with double TMD and single TMD and without TMD for load cases W1.

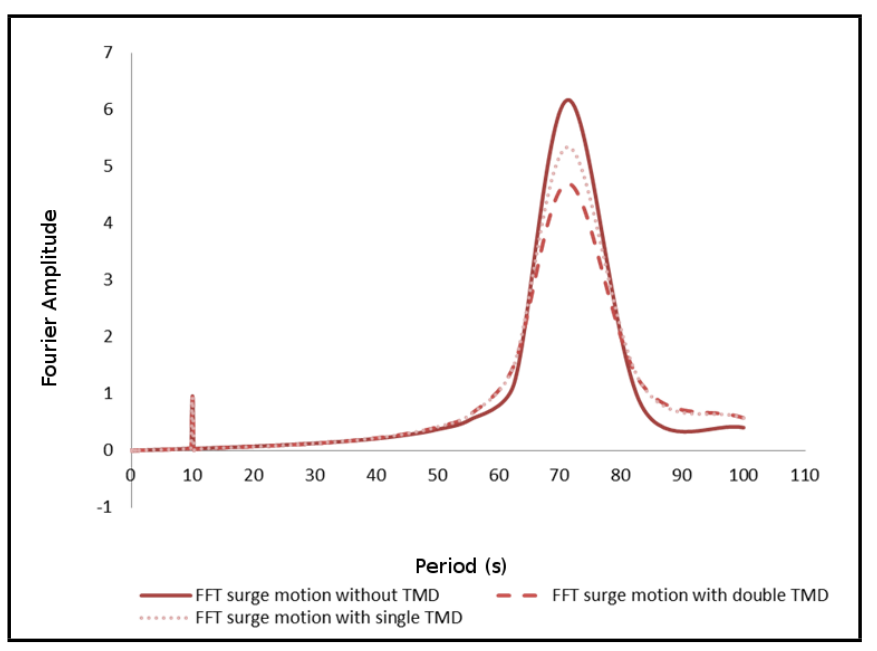

Figure 6. FFT surge response of TLP with and with double TMD and single TMD and without TMD for load case W2.

3. According to numerical studies, the mitigation percent of surge response of TLP with double TMD is more than single TMD. So, double TMD is more effective than single TMD.

4. One of the restrictions of TMD was its displacement and it needs a large space. By adding a second TMD (small mass, spring and damper) to single TMD (first TMD), the response of first TMD was reduced.

\section{REFERENCES}

1 Tabeshpour, M. R., Ataie Ashtiani, B., Seif, M. S., and Golafshani, A. A. Hydrodynamic damped pitch motion of tension leg platforms. International Journal of Marine Science and Engineering, 3(2), 91-98, (2013).

2 Donley, M. G., and Spanos, P. D. Stochastic response of a tension leg platform to viscous and potential drift forces. In Dynamic Analysis of Non-Linear Structures by the Method of Statistical Quadratization (pp. 115-146). Springer Berlin Heidelberg, (1990). https://dx.doi.org/10.1016/0266-8920(94)90024-8

3 Chatterjee, P. C., Das, P. K., and Faulkner, D. A hydrostructural analysis program for TLPs. Ocean engineering,
24(4), 313-334, (1997). https://dx.doi.org/10.1016/s00298018(96)00016-9

4 Tabeshpour, M. R., \& Malayjerdi, E. Investigation of pitch motion portion in vertical response at sides of a TensionLeg Platform. Journal of Marine Science and Application, 15(2), 175-181, (2016). https://dx.doi.org/10.1007/s11804016-1354-X

5 Alves, R. M., and Batista, R. C. Active/passive control of heave motion for TLP type offshore platform. In The Ninth International Offshore and Polar Engineering Conference. International Society of Offshore and Polar Engineers, (1999).

${ }^{6} \mathrm{Li}, \mathrm{C}$., and Zhou, D. Evaluation of multiple active levertype tuned mass dampers for structures under ground acceleration. Engineering structures, 26(3), 303-317, (2004). https://dx.doi.org/10.1016/j.engstruct.2003.10.006

7 Lee, H. H., Wong, S. H., and Lee, R. S. Response mitigation on the offshore floating platform system with tuned liquid column damper. Ocean engineering, 33(8), 1118-1142, (2006). https://dx.doi.org/10.1016/j.oceaneng.2005.06.008

${ }^{8} \mathrm{Li}, \quad$ C., and Zhu, B. Estimating double tuned mass dampers for structures under ground acceleration using a novel optimum criterion. Journal of Sound and Vibration, 298(1), 280-297, (2006). https://dx.doi.org/10.1016/j.jsv.2006.05.018

9 Rüdinger, F. Tuned mass damper with nonlinear viscous damping. Journal of sound and vibration, 300(3), 932-948, (2007). https://dx.doi.org/10.1016/j.jsv.2006.09.009

10 Golafshani, A. A., and Gholizad, A. Friction damper for vibration control in offshore steel jacket platforms. Journal of Constructional Steel Research, 65(1), 180-187, (2009). https://dx.doi.org/10.1016/j.jcsr.2008.07.008

11 Taflanidis, A. A., Angelides, D. C., and Scruggs, J. T. Simulation-based robust design of mass dampers for response mitigation of tension leg platforms. Engineering Structures, 31(4), 847-857, (2009). https://dx.doi.org/10.1016/j.engstruct.2008.11.014

12 Chandrasekaran, S., Bhaskar, K., Lino, H., and Brijit, R. Dynamic response behavior of multi-legged articulated tower with and without TMD. In Proc. International Conf. of Marine Tech.(MARTEC-2010) (pp. 11-12), (2010).

13 Chandrasekaran, S., Kumar, D., and Ramanathan, R. Dynamic response of tension leg platform with tuned mass dampers. Journal of Naval Architecture and Marine Engineering, 10(2),149-156, (2013). https://dx.doi.org/10.3329/jname.v10i2.16184

14 Chatterjee, T., and Chakraborty, S. Vibration mitigation of structures subjected to random wave forces by liquid column dampers. Ocean Engineering, 87, 151-161, (2014). https://dx.doi.org/10.1016/j.oceaneng.2014.05.004

15 Den Hartog, J.P. Mechanical vibrations. Courier Corporation, (1985). https://dx.doi.org/10.1016/c2013-0-04084-4 